Cite this: Soft Matter, 2014, 10, 3984

\title{
Aqueous worm gels can be reconstituted from freeze-dried diblock copolymer powder $\dagger$
}

\author{
M. K. Kocik, O. O. Mykhaylyk and S. P. Armes*
}

Worm-like diblock copolymer nanoparticles comprising poly(glycerol monomethacrylate) (PGMA) as a stabilizer block and poly(2-hydroxypropyl methacrylate) (PHPMA) as a core-forming block were readily synthesized at $10 \% \mathrm{w} / \mathrm{w}$ solids via aqueous dispersion polymerization at $70{ }^{\circ} \mathrm{C}$ using Reversible AdditionFragmentation chain Transfer (RAFT) chemistry. On cooling to $20^{\circ} \mathrm{C}$, soft transparent free-standing gels are formed due to multiple inter-worm interactions. These aqueous PGMA-PHPMA diblock copolymer worms were freeze-dried, then redispersed in water with cooling to $3-5{ }^{\circ} \mathrm{C}$ before warming up to 20 ${ }^{\circ} \mathrm{C}$; this protocol ensures molecular dissolution of the copolymer chains, which aids formation of a transparent aqueous gel. Rheology, SAXS and TEM studies confirm that such reconstituted gels comprise formed PGMA-PHPMA copolymer worms and they possess essentially the same physical properties determined for the original worm gels prior to freeze-drying. Such worm gel reconstitution is expected to be highly beneficial in the context of various biomedical applications, since it enables worm gels to be readily prepared using a wide range of cell growth media as the continuous aqueous phase.

Received 21st February 2014 Accepted 27th March 2014

DOI: $10.1039 / \mathrm{c} 4 \mathrm{sm} 00415 \mathrm{a}$

www.rsc.org/softmatter
The development of living radical polymerization techniques such as reversible addition-fragmentation chain transfer (RAFT) polymerization $^{33,34}$ has enabled a wide range of novel block copolymers to be prepared directly using various functional monomers without recourse to protecting group chemistry. ${ }^{35-37}$ As recently reported by our group ${ }^{38-41}$ and others, ${ }^{42-45}$ RAFT dispersion polymerization formulations offer particular advantages for the synthesis of well-defined diblock copolymer nano-objects. This is because polymerization-induced self-assembly (PISA) enables such syntheses to be conducted efficiently at relatively high solids while maintaining relatively low solution viscosity. Moreover, no post-polymerization processing step is required and the generic nature of this PISA approach has been demonstrated by the preparation of spheres, worms or vesicles in either aqueous solution, ${ }^{38,39}$ alcoholic media ${ }^{40,46}$ or $n$-alkanes..$^{41,43,47}$

In the present study, we have revisited our prototype formulation for RAFT aqueous dispersion polymerization, whereby a poly(glycerol monomethacrylate)-based macromolecular chain transfer agent (PGMA macro-CTA) is chainextended using 2-hydroxypropyl methacrylate (HPMA). ${ }^{38,39}$ The latter monomer is water-miscible, but forms a water-insoluble PHPMA block. ${ }^{38,39,48}$ This is a pre-requisite for aqueous dispersion polymerization, with the growing PHPMA driving in situ micellar self-assembly. ${ }^{38}$ Although the phase space for diblock copolymer worms is relatively narrow, this copolymer morphology can be targeted reproducibly once a detailed phase diagram is established for a given formulation. ${ }^{39}$ PGMAPHPMA worms form soft, free-standing gels at ambient temperature, ${ }^{49}$ but de-gelation occurs on cooling to $5-10{ }^{\circ} \mathrm{C}$ due to a worm-to-sphere transition. This reversible thermal
Department of Chemistry, The University of Sheffield, Dainton Building, Brook Hill, Sheffield, Yorkshire, S3 7HF, UK. E-mail: s.p.armes@shef.ac.uk

$\dagger$ Electronic supplementary information (ESI) available. See DOI: 10.1039/c4sm00415a 
transition allows convenient sterilization via cold ultrafiltration of the spherical nanoparticles, which efficiently removes any micrometer-sized bacteria that may be present ${ }^{49} \mathrm{We}$ are currently exploring whether such worm gels are sufficiently biocompatible for long-term cell storage applications. In this particular context, an important question arises: can worm gels be reformed after freeze-drying with essentially the same physical properties as the original as-synthesized aqueous worm gel? If so, this should enable worm gels to be reconstituted using a wide range of cell growth media instead of pure water. Herein we examine this important technical question using small-angle X-ray scattering (SAXS), dynamic light scattering (DLS), transmission electron microscopy (TEM) and gel rheology measurements.

\section{Experimental}

\section{Materials}

Glycerol monomethacrylate (GMA; 99.8\%) was kindly donated by GEO Specialty Chemicals (Hythe, UK). 2-Hydroxypropyl methacrylate (HPMA, 98\%, Alfa Aesar), 4,4'-azobis(4-cyanopentanoic acid) (ACVA, 98\%, Sigma-Aldrich), $\alpha, \alpha$-azoisobutyronitrile (AIBN, 99.2\%, Molekula, Dorset, UK), ethyl acetate (99.7\%, Sigma-Aldrich) and absolute ethanol (99.9\%, VWR) were used as received. 4-Cyano-4-(2-phenylethanesulfanylthiocarbonyl)sulfanylpentanoic acid (PETTC) and bis(2-phenylethanesulfanylthiocarbonyl) disulfide were synthesized using previously published methods. ${ }^{50}$

\section{Synthesis of 2-cyano-2-propyl phenethyl trithiocarbonate (PETTCCP)}

A solution of AIBN (1.23 g, $7.50 \mathrm{mmol})$ and bis-(2-phenylethanesulfanylthiocarbonyl) disulfide $(2.13 \mathrm{~g}, 5.00 \mathrm{mmol})$ were dissolved in ethyl acetate $(50 \mathrm{ml})$ and purged under $\mathrm{N}_{2}$ for $30 \mathrm{~min}$. This reaction mixture was immersed in an oil bath at $92{ }^{\circ} \mathrm{C}$ and refluxed for 16-20 h under $\mathrm{N}_{2}$. The organic phase was evaporated and purified by silica column $(9: 1$, petroleum ether : ethyl acetate) to isolate the crude product as an orange oil. This oil was washed three times with petroleum to remove traces of ethyl acetate. The purified orange oil obtained at room temperature became a yellow solid when placed in the freezer (yield: $70 \%$ ).

${ }^{1} \mathrm{H}$ NMR $\left(500 \mathrm{MHz}, \mathrm{CD}_{2} \mathrm{Cl}_{2}\right), \delta[\mathrm{ppm}]: 1.87(\mathrm{~s}, 6 \mathrm{H}), 2.99-3.03$ (m, 2H), 2.58-3.63 (m, 2H), 7.22-7.35 (m, 5H).

${ }^{13} \mathrm{C}$ NMR $\left(126 \mathrm{MHz}, \mathrm{CD}_{2} \mathrm{Cl}_{2}\right), \delta[\mathrm{ppm}]: 27.45\left(\mathrm{CH}_{3}\right), 34.52$ $\left(\mathrm{CH}_{2} \mathrm{Ph}\right), 38.51\left(\mathrm{CH}_{2} \mathrm{~S}\right), 43.19\left(\mathrm{C}\left(\mathrm{CH}_{3}\right)_{2} \mathrm{CN}\right), 120.92(\mathrm{CN}), 127.28$ ( $p-\mathrm{Ph}), 129.14(o-\mathrm{Ph} / m-\mathrm{Ph}), 129.11(o-\mathrm{Ph} / m-\mathrm{Ph}), 139.97$ (Ph$\mathrm{CH}_{2}$ ), 218.59 (CS) (ESI, Fig. S1 $\dagger$ ).

TOF MS ES ${ }^{+}\left(\mathrm{CH}_{2} \mathrm{Cl}_{2},[\mathrm{~m} / z]\right)-282\left(\left[\right.\right.$ PETTCCP $\left.+\mathrm{H}^{+}\right]$, calc. 282.05).

Elemental microanalyses [\%]. Calculated for $\mathrm{C}_{13} \mathrm{H}_{15} \mathrm{NS}_{3}$ : C 55.47, H 5.37, N 4.98, S 34.18; found: C 55.67, H 5.21, N 4.83, S 34.02 .

\section{Synthesis of PGMA 49 macro-CTA using PETTC RAFT agent}

PETTC RAFT agent (0.50 g, $1.47 \mathrm{mmol})$, ACVA ( $82.50 \mathrm{mg}, 0.29$ mmol; PETTC/ACVA molar ratio $=5.0)$ and GMA monomer
( $16.51 \mathrm{~g}, 0.10 \mathrm{mmol})$ were dissolved in anhydrous ethanol (26.50 $\mathrm{ml}$ ) in a $100 \mathrm{ml}$ round-bottomed flask and purged under $\mathrm{N}_{2}$ for $30 \mathrm{~min}$. The sealed flask was immersed into an oil bath set at 70 ${ }^{\circ} \mathrm{C}$ for $100 \mathrm{~min}$ and quenched by exposure to air. The resulting PGMA macro-CTA was purified by precipitation (twice) into excess $\mathrm{CH}_{2} \mathrm{Cl}_{2}$ from methanol. The mean degree of polymerization was calculated to be 49 by ${ }^{1} \mathrm{H}$ NMR spectroscopy. DMF GPC analysis indicated an $M_{\mathrm{n}}$ of $11100 \mathrm{~g} \mathrm{~mol}^{-1}$ and an $M_{\mathrm{w}} / M_{\mathrm{n}}$ of 1.28 ( $v s$. poly(methyl methacrylate) (PMMA) standards).

\section{Synthesis of PGMA $_{\mathbf{5}}$ macro-CTA using PETTCCP RAFT agent}

The same protocol was used as for the PETTC-mediated synthesis of PGMA $_{49}$ macro-CTA described above. PETTCCP RAFT agent ( $0.50 \mathrm{~g}, 1.78 \mathrm{mmol})$, AIBN $(58.34 \mathrm{mg}, 0.35 \mathrm{mmol}$, PETTCCP/AIBN molar ratio $=5.0)$ and GMA monomer $(19.91 \mathrm{~g}$, $0.12 \mathrm{~mol})$ were dissolved in anhydrous ethanol $(31.60 \mathrm{ml})$ and the polymerization was conducted for $2 \mathrm{~h}$. A mean degree of polymerization of 57 was calculated by ${ }^{1} \mathrm{H}$ NMR. DMF GPC analysis indicated an $M_{\mathrm{n}}$ of $14100 \mathrm{~g} \mathrm{~mol}^{-1}$ and an $M_{\mathrm{w}} / M_{\mathrm{n}}$ of 1.36 (vs. PMMA standards).

\section{Synthesis of PGMA $_{49}-$ PHPMA $_{130}$ diblock copolymer}

PGMA $_{49}$ macro-CTA (1.75 g, $0.21 \mathrm{mmol}$ ), ACVA (19.90 mg, 71.00 $\mu \mathrm{mol}$; macro-CTA/ACVA molar ratio $=3.0)$ and HPMA (4.00 g, $27.70 \mathrm{mmol})$ were dissolved in deionized $\mathrm{H}_{2} \mathrm{O}(52 \mathrm{ml}$, solid/ water ratio $=0.1$ ). This reaction mixture was purged under $\mathrm{N}_{2}$ gas for $30 \mathrm{~min}$. The sealed flask was immersed in an oil bath at $70{ }^{\circ} \mathrm{C}$ for $3 \mathrm{~h}$ and was quenched by exposure to air. ${ }^{1} \mathrm{H}$ NMR spectroscopy indicated essentially full conversion (disappearance of vinyl signals). DMF GPC analysis indicated an $M_{\mathrm{n}}$ of $35200 \mathrm{~g} \mathrm{~mol}^{-1}$ and an $M_{\mathrm{w}} / M_{\mathrm{n}}$ of 1.13 (vs. PMMA standards).

\section{Synthesis of PGMA $_{57}-$ PHPMA $_{140}$ diblock copolymer}

The protocol was essentially the same as that employed for PGMA $_{49}-$ PHPMA $_{130}$. PGMA 57 (1.86 g, $0.20 \mathrm{mmol}$ ), AIBN (10.80 $\mathrm{mg}, 66.00 \mu \mathrm{mol}$, macro-CTA/ACVA molar ratio $=3.0)$ and HPMA $(4.00 \mathrm{~g}, 27.70 \mathrm{mmol})$ were dissolved in deionized water $(53.00$ $\mathrm{ml}) .{ }^{1} \mathrm{H}$ NMR spectroscopy indicated essentially full conversion (disappearance of vinyl signals). DMF GPC analysis indicated an $M_{\mathrm{n}}$ of $41500 \mathrm{~g} \mathrm{~mol}^{-1}$ and an $M_{\mathrm{w}} / M_{\mathrm{n}}$ of 1.09 ( $v s$. PMMA standards).

\section{Protocol for redispersion of a freeze-dried copolymer worm gel}

A $10 \% \mathrm{w} / \mathrm{w}$ copolymer gel $(3.0 \mathrm{~g})$ was freeze-dried overnight, yielding $0.30 \mathrm{~g}$ of a yellow copolymer powder. This powder was ground up using a mortar and pestle and deionized water $(2.70$ $\mathrm{g}$ ) was added to produce an aqueous slurry. This was allowed to stand for $15 \mathrm{~min}$, and then placed in an ice bath for 7-10 $\mathrm{min}$ to cool down to approximately $3-5{ }^{\circ} \mathrm{C}$ to obtain a yellow liquid with small amount of foam on the top. A soft, free-standing, transparent gel was formed after allowing this copolymer sample to return to room temperature over a period of 10-15 min. 


\section{Rheology}

Rheology measurements (a TA Instruments AR-G2 rheometer equipped with a Peltier heating/cooling plate) were performed on $10 \% \mathrm{w} / \mathrm{w}$ copolymer gels using cone and plate geometry (aluminum cone with $40 \mathrm{~mm}$ diameter and $2^{\circ}$ cone). Frequency sweeps were conducted at fixed strain $(1.0 \%)$ and temperature $\left(20{ }^{\circ} \mathrm{C}\right)$. In order to study temperature response of the material, temperature sweeps in a range from $4{ }^{\circ} \mathrm{C}$ to $35{ }^{\circ} \mathrm{C}$ were performed at an angular frequency of $1.0 \mathrm{rad} \mathrm{s}^{-1}, 1.0 \%$ strain. Equilibration time of two minutes was used for one centigrade increment during the temperature ramp.

\section{Transmission electron microscopy (TEM)}

TEM images were recorded using a Phillips CM100 instrument operating at $100 \mathrm{kV}$ and equipped with a Gatan $1 \mathrm{k}$ CCD camera. A $10 \% \mathrm{w} / \mathrm{w} \mathrm{PGMA}_{57}-\mathrm{PHPMA}_{140}$ copolymer worm gel was diluted to $0.20 \% \mathrm{w} / \mathrm{w}$ and stirred overnight to ensure complete worm dispersion. Copper/palladium TEM grids (Agar Scientific, UK) were surface-coated in-house to yield a thin amorphous carbon film. The grids were plasma glow-discharged over 20-30 s to obtain a hydrophilic surface. Each sample $(1.0 \mu \mathrm{l})$ was placed on the grid using a micropipette and dried under ambient conditions. A dilute aqueous solution of uranyl formate $(0.75 \% \mathrm{w} / \mathrm{w})$ was used as a stain ( $9 \mu \mathrm{l}$ of stain, blotted after $20 \mathrm{~s})$. Each grid was then carefully dried using a vacuum hose. A slightly different protocol was used for the $10 \% \mathrm{w} / \mathrm{w} \mathrm{PGMA}_{49}-\mathrm{PHPMA}_{130}$ copolymer worm gel. This worm gel was diluted to $0.20 \% \mathrm{w} / \mathrm{w}$ solids using dilute aqueous $\mathrm{HCl}$ to maintain a solution $\mathrm{pH}$ of 3.6. Each TEM sample grid was then prepared as described above.

\section{Small-angle X-ray scattering (SAXS)}

SAXS curves for $10 \% \mathrm{w} / \mathrm{w}$ copolymer worm gels were obtained using a Bruker AXS Nanostar instrument (camera length $1.06 \mathrm{~m}$, $\mathrm{CuK} \alpha$ radiation) equipped with a HiStar area detector and a semi-transparent beam-stop. SAXS patterns were recorded over a scattering vector $(\boldsymbol{q})$ range of $0.1 \mathrm{~nm}^{-1}<\boldsymbol{q}<2.0 \mathrm{~nm}^{-1}$. A liquid cell with a polytetrafluoroethylene spacer (1.0 $\mathrm{mm}$ thickness) covered by two mica windows (thickness $=25 \mu \mathrm{m}$ ) on both sides was used as a sample holder. The cell was connected to an ethylene glycol circulator preset to the required temperature. Dry nitrogen gas was used to reduce water condensation on both cell windows at low temperatures.

\section{Visible absorption spectroscopy}

The transparency of $10 \% \mathrm{w} / \mathrm{w}$ worm copolymer gels was assessed using a Varian Cary 300Bio UV-visible spectrophotometer equipped with a Peltier temperature-controlled multicell holder. Each gel was equilibrated for $10 \mathrm{~min}$ at $20^{\circ} \mathrm{C}$ before recording its visible absorption spectrum.

\section{Results and discussion}

Freeze-drying (or lyophilization) is widely used for the facile isolation of antibiotics, proteins or vaccines, and also for certain foodstuffs such as 'instant' coffee. This technique often ensures more stable products and longer preservation times. ${ }^{51,52}$ Freezedrying is also commonly used in both biology and chemistry to isolate liposomes, proteins, colloids and water-soluble polymers from aqueous solution. For example, Cabane et al. reported that this process can also be used to increase the size of lipid-based vesicles by increasing their concentration. ${ }^{53}$ In the context of the present work, Cho and Chung reported that cholesterol-based polymeric vesicles containing $\left[{ }^{14} \mathrm{C}\right]$ sucrose could be reconstituted after freeze-drying on addition of water, with $90 \%$ of the sucrose payload remaining within the redispersed vesicles. ${ }^{54}$ Furthermore, Qi and co-workers reported that freeze-dried poly(ethylene glycol)-stabilized ceria nanoparticles can be readily redispersed in various solvents with good reproducibility. ${ }^{55}$ However, to the best of our knowledge, the reconstitution of freeze-dried diblock copolymer worm gels in aqueous solution has not yet been investigated. In order to evaluate such formulations, PGMA-PHPMA diblock copolymer worms were prepared at $10 \% \mathrm{w} / \mathrm{w}$ solids via RAFT aqueous dispersion polymerization at $70{ }^{\circ} \mathrm{C}$, as previously reported by Blanazs et al. ${ }^{49}$ (Scheme 1). On cooling to $20^{\circ} \mathrm{C}$, the worms form soft, free-standing transparent gels that undergo de-gelation on cooling because of a reversible worm-to-sphere transition..$^{49}$ The two diblock copolymer compositions explored in the present work were PGMA $_{49}-\mathrm{PHPMA}_{130}$ and $\mathrm{PGMA}_{57}-\mathrm{PHPMA}_{140}$, which were prepared using two different trithiocarbonate RAFT CTAs.

Both as-synthesized $10 \% \mathrm{w} / \mathrm{w}$ worm gels were freeze-dried overnight, resulting in pale yellow copolymer powders. In principle, such lyophilization should remove the aqueous continuous phase, but leave the copolymer worm particles intact. ${ }^{5,57}$ Grinding using a mortar and pestle degraded the fibrous nature of the freeze-dried worms and produced a freeflowing powder. It was found empirically that this processing step aided subsequent copolymer rehydration: free-flowing powder could be redispersed in water much more effectively than the initial fibrous powder.

An aqueous slurry (Scheme 2, image 3) was formed after addition of water. TEM analysis (ESI, Fig. S2a†) of the rehydrated copolymer revealed that this initial slurry contained spheres, a minor population of worms and larger colloidal aggregates. In our initial experiments, the freeze-dried $\mathrm{PGMA}_{49}{ }^{-}$ PHPMA $_{130}$ diblock copolymer was dispersed in deionized water at room temperature $\left(20^{\circ} \mathrm{C}\right)$ and allowed to stand for several days. In the first few hours after rehydration, a turbid suspension was obtained. However, over the next 1-2 days a transparent free-standing gel eventually formed that contained some millimeter-sized trapped air bubbles (denoted $\mathrm{PGMA}_{49}{ }^{-}$ $\mathrm{PHPMA}_{130}$-RT).

Lowering the solution temperature by immersing the initial aqueous copolymer slurry in an ice bath significantly reduced the time required for gel reconstitution from 1-2 days to approximately $20 \mathrm{~min}$. Thus this cooling stage was used as the standard protocol to redisperse the freeze-dried diblock copolymer worms (denoted PGMA $_{49}-\mathrm{PHPMA}_{130}$-FD or $\mathrm{PGMA}_{57^{-}}$ PHPMA $_{140}-\mathrm{FD}$ ). Each step of this gel reconstitution process is summarized in Scheme 2 .

TEM studies (Fig. 1a and b, plus Fig. S3a and b in the ESI $\dagger$ ) confirmed that both the original and reconstituted gels 


$$
\sum_{\mathrm{OH}}^{\mathrm{OH}}
$$

Scheme 1 Synthesis of two PGMA PHPMA $_{m}$ diblock copolymers ( $n=49, m=130$ and $n=57, m=140$ ) via RAFT aqueous dispersion polymerization at $70^{\circ} \mathrm{C}$. The R end-group varies according to the nature of the RAFT CTA (either PETTC or PETTCCP, experimental).

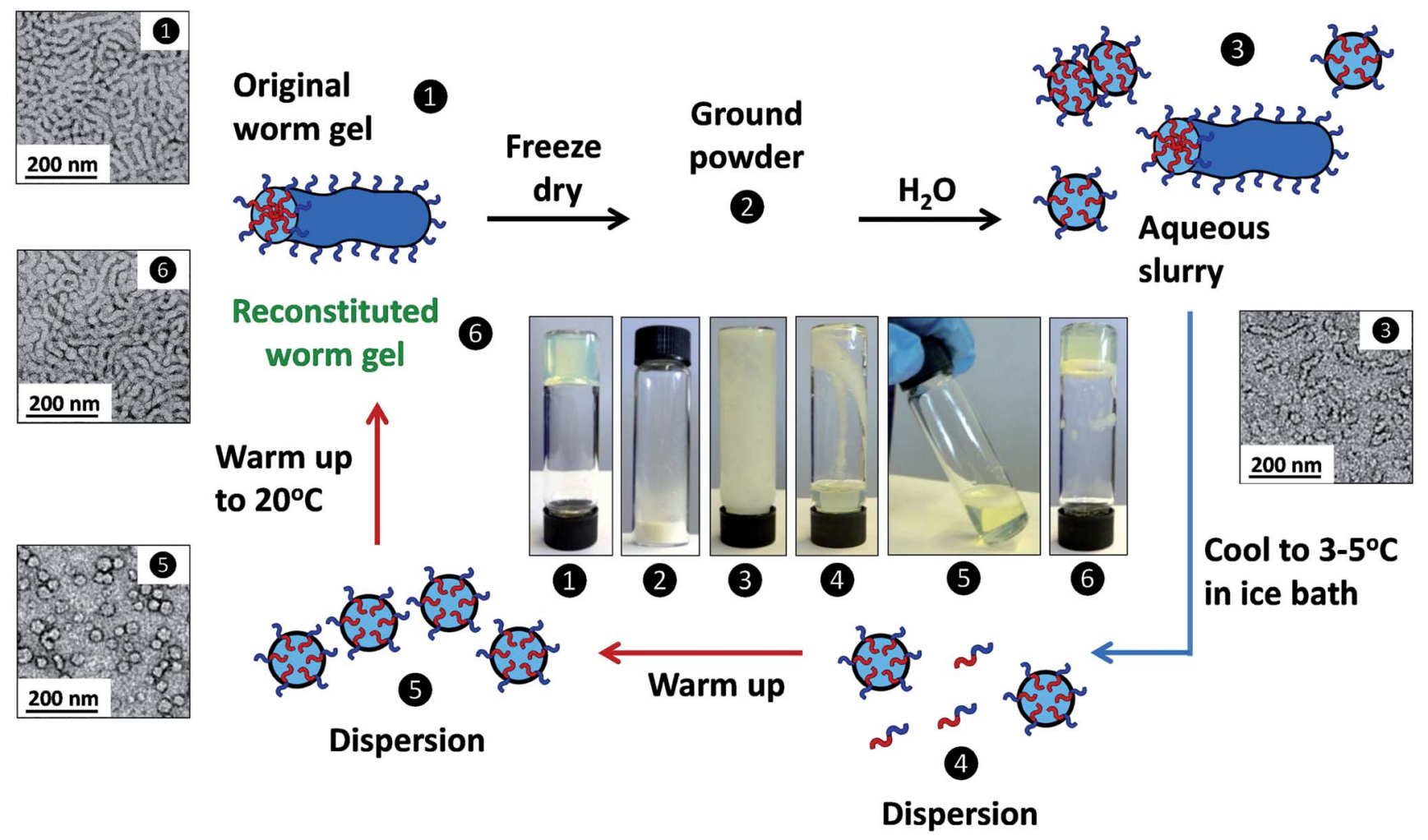

Scheme 2 Schematic representation of the standard protocol used to redisperse the freeze-dried PGMA-PHPMA diblock copolymer worms: (1) original worm gel, (2) freeze-drying overnight, followed by grinding the fibrous pale yellow powder using a mortar and pestle, (3) initial dispersion as an aqueous slurry, (4) cooling to $3-5^{\circ} \mathrm{C}$ using an ice bath, (5) allowing the cold copolymer dispersion to warm up to room temperature (20 ${ }^{\circ} \mathrm{C}$ ), (6) the reconstituted soft, transparent, free-standing worm gel.
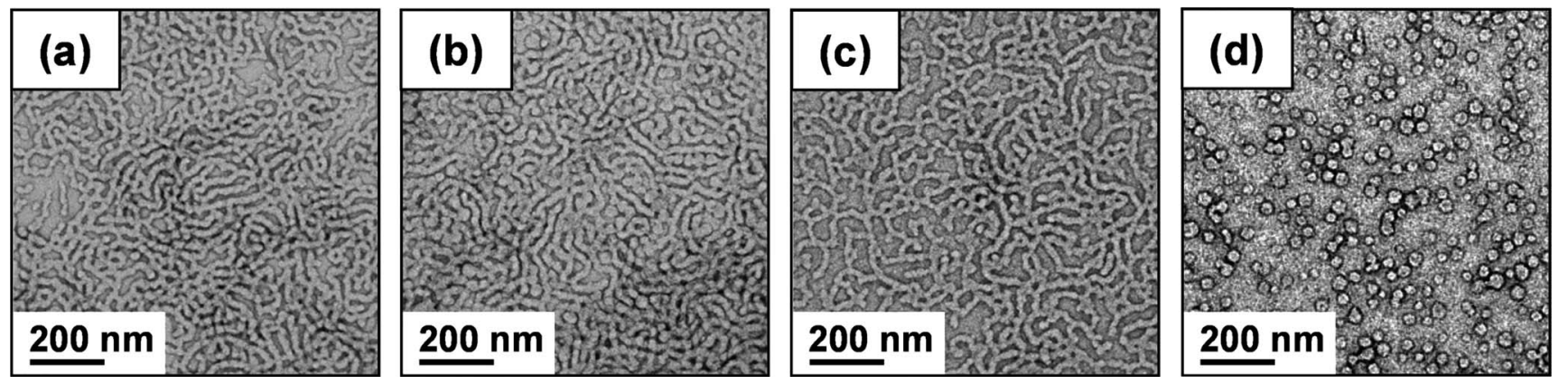

Fig. 1 Transmission electron microscopy images obtained for: (a) original PGMA $57-$ PHPMA $_{140}$ worm gel, (b) reconstituted gel using the standard protocol described in Scheme 2 (denoted PGMA ${ }_{57}-\mathrm{PHPMA}_{140}-\mathrm{FD}$ ), (c) reconstituted worm gel after freezing the aqueous slurry at $-25^{\circ} \mathrm{C}$ and allowing to warm up to $20^{\circ} \mathrm{C}$ (denoted PGMA $57-\mathrm{PHPMA}_{140}-\mathrm{FDF}$ ), (d) reconstituted PGMA ${ }_{57}-\mathrm{PHPMA}_{140}-\mathrm{FD}$ gel was cooled to $5^{\circ} \mathrm{C}$ and became a free-flowing dispersion; TEM grid preparation was carried out at this temperature. 

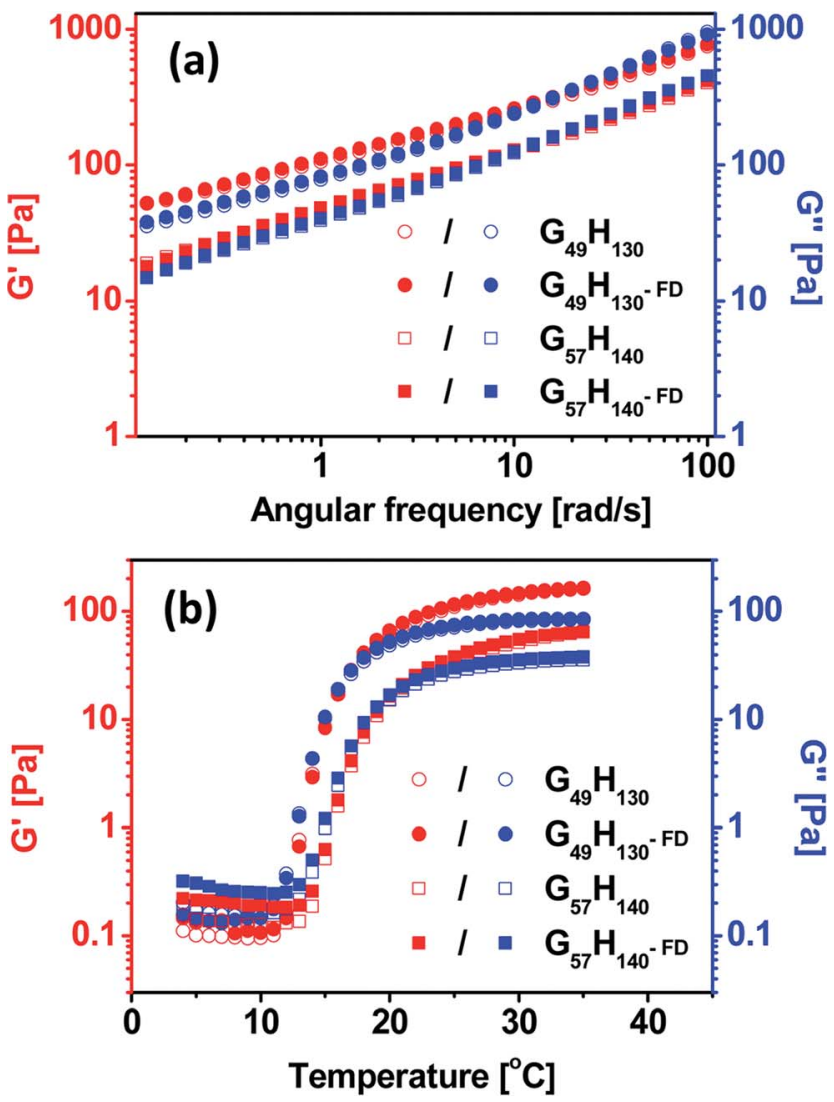

Fig. 2 Rheological studies of the original PGMA $49-\mathrm{PHPMA}_{130}$ and PGMA $57-$ PHPMA $_{140}$ worm gels (denoted $\mathrm{G}_{49} \mathrm{H}_{130}$ and $\mathrm{G}_{57} \mathrm{H}_{140}$ ) and the corresponding reconstituted worm gels obtained after freezedrying $\left(\mathrm{G}_{49} \mathrm{H}_{130}-\mathrm{FD}\right.$ and $\left.\mathrm{G}_{57} \mathrm{H}_{140}-\mathrm{FD}\right)$ : (a) frequency sweep for $\mathrm{G}^{\prime}$ and $G^{\prime \prime}$ at $20^{\circ} \mathrm{C}$ at an applied strain of $1.0 \%$; (b) temperature sweep for $G^{\prime}$ and $G^{\prime \prime}$ from $4{ }^{\circ} \mathrm{C}$ to $35^{\circ} \mathrm{C}$ at a fixed frequency of $1.0 \mathrm{rad} \mathrm{s}^{-1}$ and $1.0 \%$ strain.

comprise diblock copolymer worms. Free-standing $\mathrm{PGMA}_{49}{ }^{-}$ PHPMA $_{130}, \quad$ PGMA $_{57}-$ PHPMA $_{140}, \quad$ PGMA $_{49}-$ PHPMA $_{130}$-FD or $\mathrm{PGMA}_{57}-\mathrm{PHPMA}_{140}$-FD worm gels at $20{ }^{\circ} \mathrm{C}$ became free-flowing liquids on cooling to $5{ }^{\circ} \mathrm{C}$ (Fig. $1 \mathrm{~b}$ and $\mathrm{d}$ ). This is due to a wormto-sphere morphological transition, as previously reported by Blanazs et al. for a PGMA $_{54}-$ PHPMA $_{140}$ worm gel. ${ }^{49}$ This thermoresponsive behavior was verified for $\mathrm{PGMA}_{49}-\mathrm{PHPMA}_{130}$ and PGMA $_{57}-$ PHPMA $_{140}$ worms using DLS (Table S1 and Fig. S4 in the ESI $\dagger$ ) and/or SAXS.

Rheology and SAXS studies were conducted in order to ascertain whether the reconstituted worm gels obtained after freeze-drying had the same physical properties as the original worm gels. Rheological measurements confirmed that almost identical frequency dependence of loss modulus and storage modulus, $G^{\prime}$ and $G^{\prime \prime}$, respectively, are obtained for the worm gels before and after freeze-drying (Fig. 2a). Similarly, the temperature response studies of $G^{\prime}$ and $G^{\prime \prime}$ suggest that the critical gelation temperature for the worm-to-sphere remains essentially unchanged (Fig. 2b) and that there is little or no hysteresis (ESI, Fig. S5 $\dagger$ ) between the heating and cooling cycles for each of the four copolymer samples investigated.
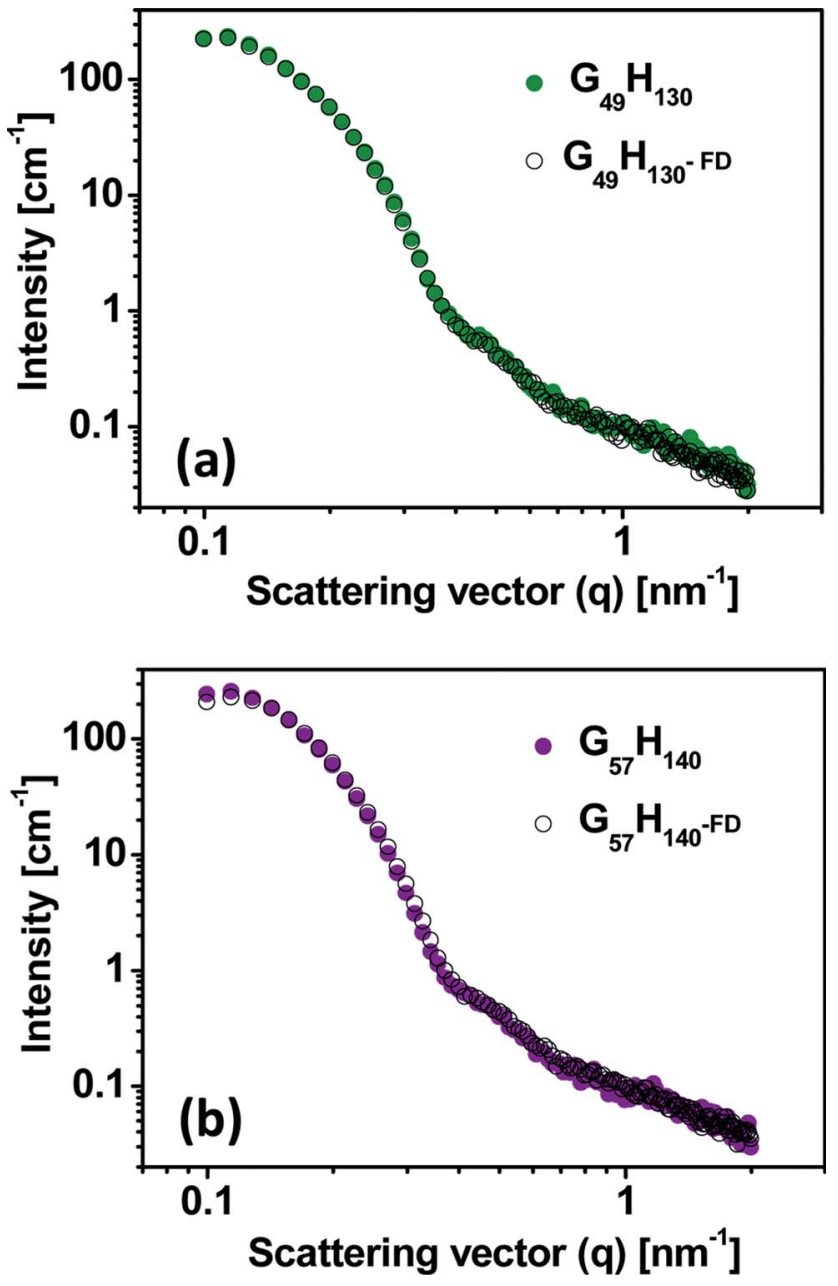

Fig. 3 SAXS curves obtained at $10 \% \mathrm{w} / \mathrm{w}$ copolymer concentration and $20^{\circ} \mathrm{C}$ for: (a) the original PGMA $49-\mathrm{PHPMA}_{130}$ worm gel (denoted $\mathrm{G}_{49} \mathrm{H}_{130}$ ) and the corresponding reconstituted worm gel after freezedrying ( $P G M A_{49}-P_{H P M A} 130-F D$, denoted $\mathrm{G}_{49} \mathrm{H}_{130}-\mathrm{FD}$ ); (b) the original $\mathrm{PGMA}_{57}-\mathrm{PHPMA}_{140}$ worm gel (denoted $\mathrm{G}_{57} \mathrm{H}_{140}$ ) and the corresponding reconstituted worm gel after freeze-drying $\left(\mathrm{PGMA}_{57}-\right.$ $\mathrm{PHPMA}_{140}-\mathrm{FD}, \mathrm{G}_{57} \mathrm{H}_{140}-\mathrm{FD}$ ).

SAXS data obtained for the original and reconstituted worm gels clearly indicate that the final worm morphology obtained after freeze-drying is indistinguishable from that of the original worms, since the $I(\boldsymbol{q})$ vs. $\boldsymbol{q}$ plots almost overlay for both PGMA $_{49}-$ PHPMA $_{130}$ and PGMA $_{57}-$ PHPMA $_{140}$ (Fig. 3). This is in agreement with TEM data and confirmed that the reconstituted gel obtained after freeze-drying is physically identical to the original worm gel (Fig. 1a and b, and Fig. S3a and b in the ESI $\dagger$ ).

As already noted above, lowering the solution temperature enabled significantly faster reconstitution of worm gels from freeze-dried copolymer powder. Thus this important parameter was investigated in more detail. An initial aqueous slurry of diblock copolymer was placed in a $-25{ }^{\circ} \mathrm{C}$ freezer and became completely frozen $\left(\mathrm{PGMA}_{49}-\mathrm{PHPMA}_{130}-\mathrm{FDF}\right.$ or $\mathrm{PGMA}_{57}-$ $\left.\mathrm{PHPMA}_{140}-\mathrm{FDF}\right)$. In this case, gel reconstitution appears to differ from the standard protocol: the freeze-dried copolymer dissolved molecularly under these conditions, which allows 

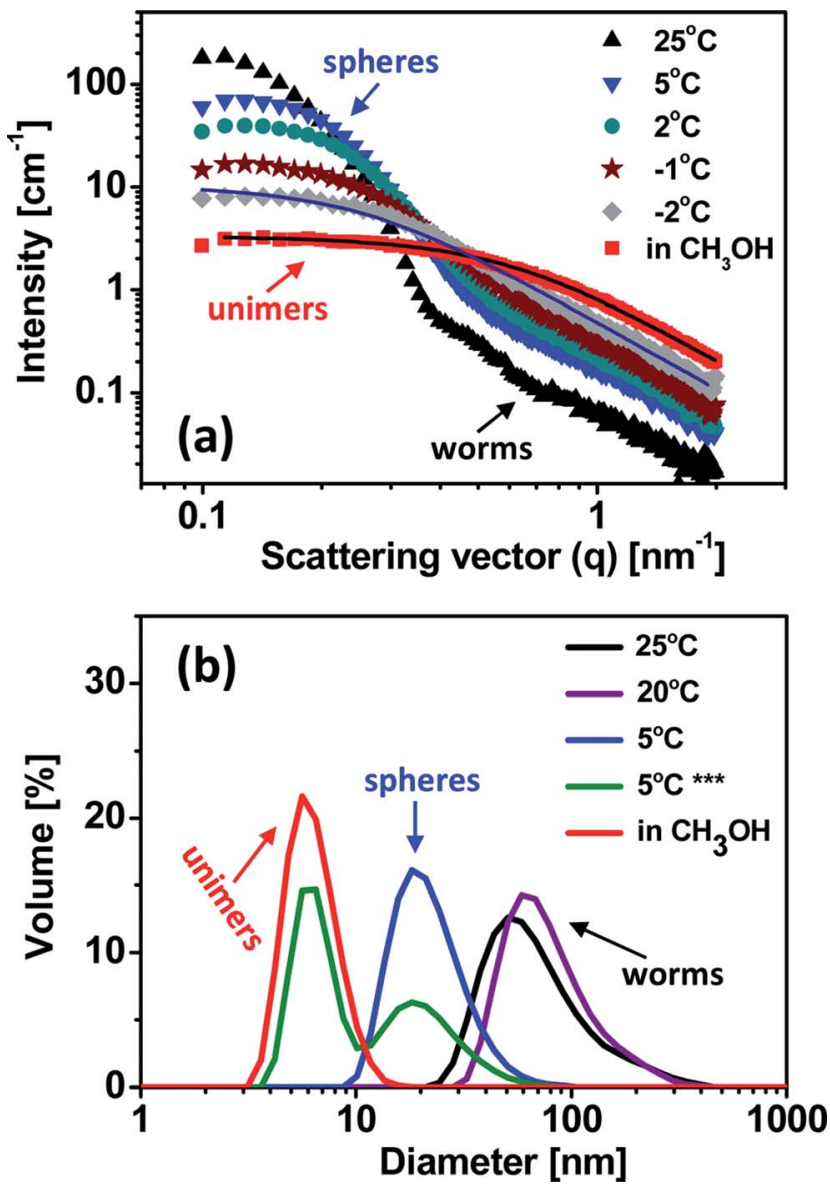

Fig. 4 (a) Small-angle $X$-ray scattering patterns recorded for a $10 \% \mathrm{w} /$ $w$ aqueous dispersion of PGMA $_{57}-$ PHPMA $_{140}$ obtained after freezedrying and reconstitution using the standard protocol. /(q) vs. $q$ plots were recorded at $25^{\circ} \mathrm{C}, 5^{\circ} \mathrm{C}, 2^{\circ} \mathrm{C},-1{ }^{\circ} \mathrm{C}$, and $-2{ }^{\circ} \mathrm{C}$; the change in slope of the SAXS curve from a negative gradient (black triangles) to zero gradient (blue inverted triangles) observed for $q<0.2 \mathrm{~nm}^{-1}$ indicates that the worm-to-sphere transition for this copolymer occurs on cooling from $25^{\circ} \mathrm{C}$ to $5^{\circ} \mathrm{C}$. Further cooling from $5{ }^{\circ} \mathrm{C}$ to -2 ${ }^{\circ} \mathrm{C}$ leads to near-molecular dissolution of the copolymer chains. As a comparison, SAXS patterns of a $10 \% \mathrm{w} / \mathrm{w}$ solution of the same diblock copolymer molecularly dissolved in methanol at $20{ }^{\circ} \mathrm{C}$ are given (red squares). Solid lines represent fittings to SAXS data by using Gaussian coil model (see main text and ESI† for further details). (b) DLS particle size distributions (calculated by volume\%; see ESI and also Fig. S4 $\uparrow$ ) obtained for a $0.20 \%$ aqueous dispersion of $\mathrm{PGMA}_{57}-\mathrm{PHPMA}_{140}-\mathrm{FD}$ at $25,20,5{ }^{\circ} \mathrm{C}$ and also for a $10 \%$ methanolic solution of $\mathrm{PGMA}_{57}-$ $\mathrm{PHPMA}_{140}-\mathrm{FD}$ at $20^{\circ} \mathrm{C}$. $* * *$ Sample was equilibrated for $1 \mathrm{~h}$ at $5{ }^{\circ} \mathrm{C}$.

more controlled, albeit slower, self-assembly. Thus the individual copolymer chains (or unimers) self-assemble to form first spheres and then worms (see the SAXS curves shown in Fig. 4a and also DLS data in Fig. 4b). However, the gel strength determined for the $\mathrm{PGMA}_{49}-\mathrm{PHPMA}_{130}$-FDF worm gel is significantly lower than that of the original $\mathrm{PGMA}_{49}-\mathrm{PHPMA}_{130}$ worm gel. This may indicate that shorter worms are formed using this protocol. ${ }^{48}$

The series of SAXS curves shown in Fig. 4a reveal the changes in morphology (from worms to spheres to unimers) observed for a $10 \% \mathrm{w} / \mathrm{w}$ aqueous dispersion of $\mathrm{PGMA}_{57}-\mathrm{PHPMA}_{140}$-FD on lowering the temperature from $25{ }^{\circ} \mathrm{C}$ to $-2{ }^{\circ} \mathrm{C}(N . B$. due to the

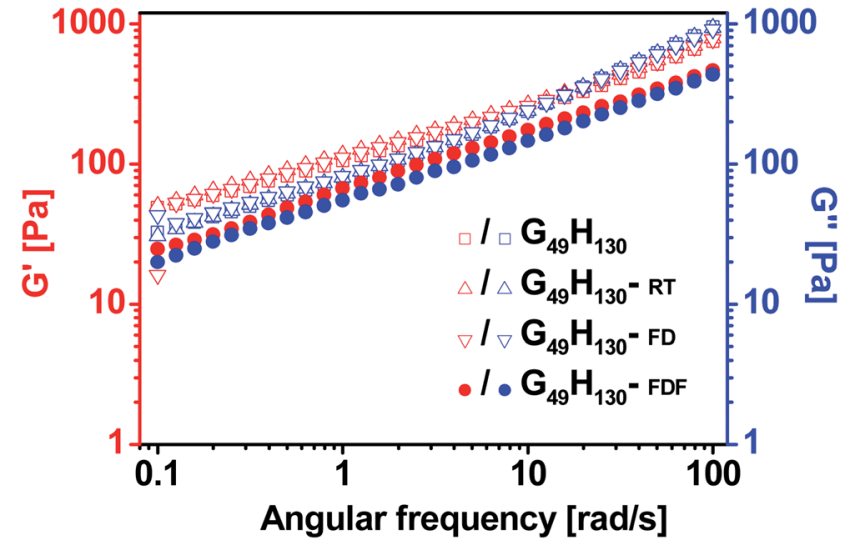

Fig. 5 Frequency dependence recorded at $20^{\circ} \mathrm{C}$ for $G^{\prime}$ and $G^{\prime \prime}$ at an applied strain of $1.0 \%$ for an original worm gel $\left(\mathrm{PGMA}_{49}-\mathrm{PHPMA}_{130}\right)$ and three reconstituted gels prepared using three different protocols: (i) original worm gel $\left(\mathrm{PGMA}_{49}-\mathrm{PHPMA}_{130}\right)$, (ii) reconstituted gel prepared at $20{ }^{\circ} \mathrm{C}\left(\mathrm{PGMA}_{49}-\mathrm{PHPMA}_{130}-\mathrm{RT}\right)$, (iii) reconstituted worm gels obtained after freeze-drying using the standard protocol $\left(\mathrm{PGMA}_{49}-\mathrm{PHPMA}_{130}-\mathrm{FD}\right)$, (iv) reconstituted worm gel after freezing the aqueous slurry at $-25{ }^{\circ} \mathrm{C}$ and warming up to $20{ }^{\circ} \mathrm{C}\left(\mathrm{PGMA}_{49}-\right.$ $\mathrm{PHPMA}_{130}-$ FDF). PGMA and PHPMA are abbreviated to $\mathrm{G}$ and $\mathrm{H}$.
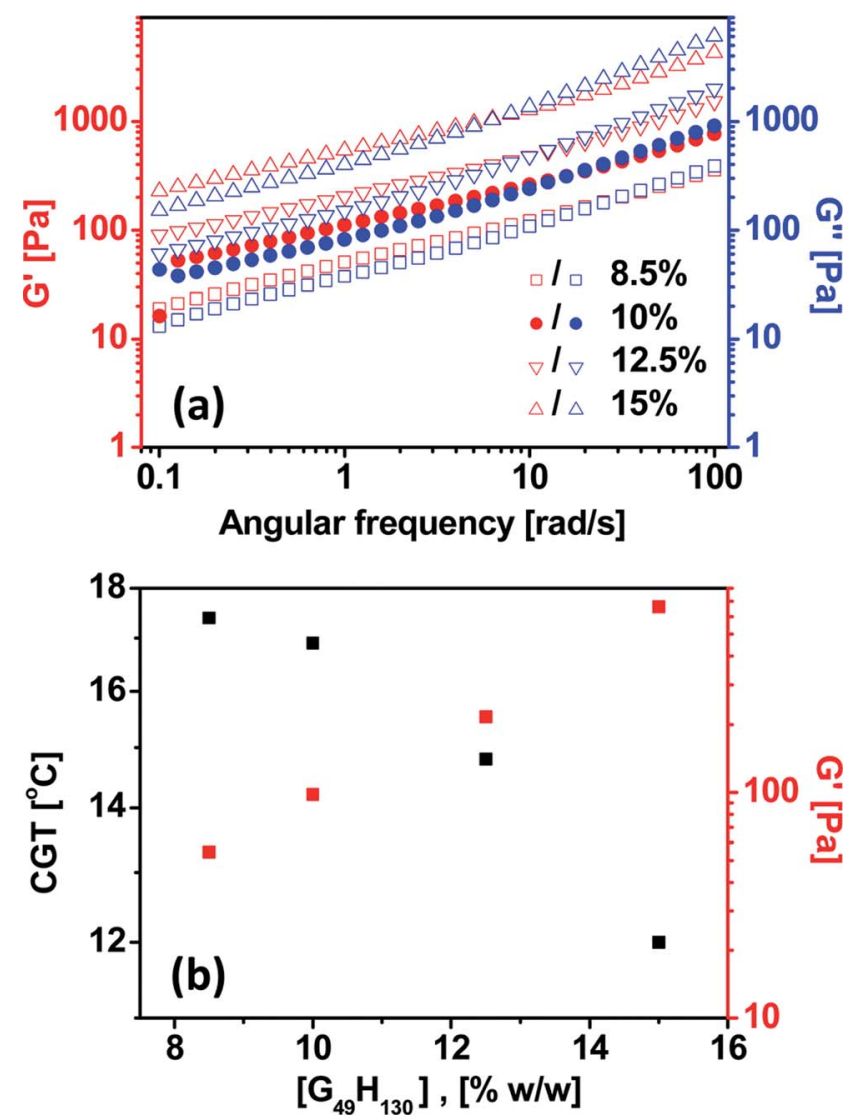

Fig. 6 Rheological studies on diblock copolymer worm gels. (a) Frequency dependence of $G^{\prime}$ and $G^{\prime \prime}$ at $20^{\circ} \mathrm{C}$ and an applied strain of $1.0 \%$ for the $\mathrm{PGMA}_{49}-\mathrm{PHPMA}_{130}-\mathrm{FD}$ worm gel redispersed at four copolymer concentrations $(8.5$ to $15 \% \mathrm{w} / \mathrm{w})$. (b) Variation of critical gelation temperature (CGT) and gel strength $\left(G^{\prime}\right)$ with copolymer concentration for four reconstituted $\mathrm{PGMA}_{49}-\mathrm{PHPMA}_{130}-\mathrm{FD}$ gels prepared at $8.5,10,12.5$ and $15 \% \mathrm{w} / \mathrm{w}$ (denoted $\mathrm{G}_{49} \mathrm{H}_{130}-\mathrm{FD}$ ). 
copolymer presence freezing of water does not occur at this latter temperature). The morphology of these nano-objects was confirmed by TEM studies (Fig. 1b and d) and is also consistent with DLS data (Fig. $4 \mathrm{~b}$ and Table $\mathrm{S} 1$ and Fig. S4 in the ESI $\dagger$ ). A fit to the SAXS pattern of the PGMA ${ }_{57}-\mathrm{PHPMA}_{140}$ aqueous solution at $-2{ }^{\circ} \mathrm{C}$ (Fig. 4a, grey diamonds) by using a Gaussian polymer chain model (ESI $\dagger$ ) suggests that the sphere micelles in aqueous solution do not completely disintegrate into single molecules upon cooling to $-2{ }^{\circ} \mathrm{C}$ (ESI $\dagger$ ). Comparison with the fitted SAXS curve obtained for the same diblock copolymer molecularly dissolved as individual copolymer chains in methanol (Fig. 4a, red squares) suggests that near-molecular dissolution is achieved in water at around $-2{ }^{\circ} \mathrm{C}(N$.B. the aqueous copolymer dispersion becomes frozen below this temperature). This is consistent with previously published data on PHPMA-based diblock copolymers. ${ }^{49,58}$

Significantly lower $G^{\prime}$ values for the reconstituted $\mathrm{PGMA}_{49^{-}}$ PHPMA $_{130}$-FDF and PGMA $57-$ PHPMA $_{140}$-FDF gels compared to the original $\mathrm{PGMA}_{49}-\mathrm{PHPMA}_{130}$ or $\mathrm{PGMA}_{57}-\mathrm{PHPMA}_{140}$ gels (Fig. 5 or Fig. S6a in the ESI $\dagger$ ) suggest either shorter worms or perhaps fewer/weaker inter-worm interactions. However, TEM studies (Fig. 1a and c and Fig. S3a and $\mathrm{c}$ in the ESI $\dagger$ ) did not suggest any obvious reduction in mean worm length.

In contrast, the slightly higher $G^{\prime}$ observed for the $\mathrm{PGMA}_{49}$ PHPMA $_{130}$-RT gel compared to the original PGMA $_{49}-\mathrm{PHPMA}_{130}$ (Fig. 5 and also Fig. S6a in the ESI $\dagger$ ) may indicate longer worms, which would result in more/stronger inter-worm interactions.

Although the $\mathrm{PGMA}_{49}-\mathrm{PHPMA}_{130}$-FDF worm gel is slightly more transparent than the $\mathrm{PGMA}_{49}-\mathrm{PHPMA}_{130}$-FD (Fig. S7a in the ESI $\dagger$ ), the visual appearance of these two gels is rather similar. Hence the freezing step at $-25{ }^{\circ} \mathrm{C}$ is not utilized for the standard protocol depicted in Scheme 2. The latter conditions allow the convenient production of a reconstituted worm gel with comparable physical properties to the original worm gel within a relatively short time scale and avoids problems such as trapped air bubbles.

To further probe the mechanism of worm gel reformation, freeze-dried worms $\left(\mathrm{PGMA}_{57}-\mathrm{PHPMA}_{140}-\mathrm{CH}_{3} \mathrm{OH}\right)$ were molecularly dissolved in methanol, followed by solvent evaporation. Thus this protocol ensures complete destruction of the original worm morphology. Water was then added to the sample vial, which was cooled in the freezer at $-25^{\circ} \mathrm{C}$ prior to warming up to $20{ }^{\circ} \mathrm{C}$. The majority of this sample formed a reconstituted gel, as expected. However, this gel was weaker than expected as judged by rheology (Fig. S6b in the ESI $\dagger$ ), which was attributed to a minor fraction of non-dispersed copolymer remaining on the walls of the sample vial. TEM analysis of this diluted $\mathrm{PGMA}_{57}$ $\mathrm{PHPMA}_{140}-\mathrm{CH}_{3} \mathrm{OH}$ gel revealed that it consisted of a mixture of worms and spheres, rather than pure worms (Fig. S2b in the ESI $\dagger$ ). This observation is consistent with the lower $G^{\prime}$ value indicated by the rheology studies.

Successful gel reconstitution after copolymer dissolution in methanol (or near-molecular dissolution at $-2{ }^{\circ} \mathrm{C}$ ) suggests that the worms formed in aqueous solution is the thermodynamically-favored morphology for this particular copolymer composition, rather than merely a kinetically-trapped morphology.
Gel reconstitution from freeze-dried copolymer worms enables important physical properties such as the gel strength $\left(G^{\prime}\right)$ and critical gelation temperature (CGT) to be tuned by simply varying the copolymer concentration (Fig. 6b). Thus increasing the copolymer content from 8.5 to $15 \%$ produces a monotonic reduction in the CGT from $17.5{ }^{\circ} \mathrm{C}$ to $12{ }^{\circ} \mathrm{C}$ and a linear increase in gel strength, which is consistent with recently published data. ${ }^{48}$

The water content of hydrogels may vary over time because of either syneresis (i.e. the spontaneous expulsion of water from the gel) or evaporative losses. Gel reconstitution from freezedried copolymer powder should minimize this problem and also suggests that these worm gels may be recyclable after initial use. In this context, it is perhaps also noteworthy that facile (re) sterilization of these aqueous worm gels can be achieved via cold ultrafiltration, as recently described by Blanazs et al. ${ }^{49}$ One potentially decisive advantage offered by the reconstitution of freeze-dried worms is that this protocol enables gels to be conveniently prepared using bespoke aqueous media such as phosphate-buffered saline or various commercial cell growth medium (e.g. standard cell growth media such as DMEM or RPMI, with or without foetal calf serum, or more complex formulations used for stem cell growth). ${ }^{\mathbf{5 9 , 6 0}}$ This is expected to be beneficial for various cell biology applications for these worm gels, which exhibit good biocompatibility. ${ }^{49}$

\section{Conclusions}

PGMA-PHPMA diblock copolymer worm gels can be reconstituted from freeze-dried worms. Gel formation is aided by initial dissolution in water with cooling to $3-5{ }^{\circ} \mathrm{C}$, since this leads to near-molecular dissolution of the diblock copolymer chains. Self-assembly to form individual worms, and ultimately soft free-standing transparent gels, occurs on warming the cold copolymer aqueous solution/dispersion up to ambient temperature. SAXS, TEM and rheology studies indicate that the particle size/morphology, transparency and gel strength of the reconstituted worm gels are almost indistinguishable from the original worm gels prior to freeze-drying. These findings are important, because these worm gels have potential applications as cell storage media. In this context, the ability to readily reconstitute worm gels within a range of cell growth media is expected to be an important advantage and also suggests that worm gel recycling should be feasible.

\section{Acknowledgements}

The Swiss National Science Foundation (SNSF) is thanked for funding an 18-month post-doctoral fellowship for MKK. SPA also acknowledges an ERC Advanced Investigator grant (PISA 320372).

\section{References}

1 R. R. Balmbra, J. S. Clunie and J. F. Goodman, Nature, 1969, 222, 1159-1160. 
2 J. N. Israelachvili, D. J. Mitchell and B. W. Ninham, J. Chem. Soc., Faraday Trans. 2, 1976, 72, 1525-1568.

3 L. Zhang and A. Eisenberg, Science, 1995, 268, 1728-1731.

4 Y.-Y. Won, H. T. Davis and F. S. Bates, Science, 1999, 283, 960-963.

5 Y. Zheng, Y.-Y. Won, F. S. Bates, H. T. Davis, L. E. Scriven and

Y. Talmon, J. Phys. Chem. B, 1999, 103, 10331-10334.

6 Y. Mai and A. Eisenberg, Acc. Chem. Res., 2012, 45, 16571666.

7 J. E. Puskas and Y. Chen, Biomacromolecules, 2004, 5, 11411154.

8 J. E. Puskas and G. Kaszas, Rubber Chem. Technol., 1996, 69, 462-475.

9 P. Alexandridis and T. Alan Hatton, Colloids Surf., A, 1995, 96, 1-46.

10 T. Tadros, Adv. Colloid Interface Sci., 2009, 147-148, 281299.

11 T. F. Tadros, Applied Surfactants: Principles and Applications, Wiley-VCH, Weinheim, 2005.

12 C. Booth and D. Attwood, Macromol. Rapid Commun., 2000, 21, 501-527.

13 J. Godward, F. Heatley and C. Booth, J. Chem. Soc., Faraday Trans., 1995, 91, 1491-1496.

14 H. Li, G.-E. Yu, C. Price, C. Booth, E. Hecht and H. Hoffmann, Macromolecules, 1997, 30, 1347-1354.

15 Y. S. Thio, J. Wu and F. S. Bates, J. Polym. Sci., Part B: Polym. Phys., 2009, 47, 1125-1129.

16 J. Liu, Z. J. Thompson, H.-J. Sue, F. S. Bates, M. A. Hillmyer, M. Dettloff, G. Jacob, N. Verghese and H. Pham, Macromolecules, 2010, 43, 7238-7243.

17 M. Motornov, Y. Roiter, I. Tokarev and S. Minko, Prog. Polym. Sci., 2010, 35, 174-211.

18 M. C. A. Stuart and E. J. Boekema, Biochim. Biophys. Acta, Biomembr., 2007, 1768, 2681-2689.

19 Z. Chu, C. A. Dreiss and Y. Feng, Chem. Soc. Rev., 2013, 42, 7174-7203.

20 T. P. Lally and C. Price, Polymer, 1974, 15, 325-326.

21 P. A. Canham, T. P. Lally, C. Price and R. B. Stubbersfield, J. Chem. Soc., Faraday Trans. 1, 1980, 76, 1857-1867.

22 B. M. Discher, Y.-Y. Won, D. S. Ege, J. C.-M. Lee, F. S. Bates, D. E. Discher and D. A. Hammer, Science, 1999, 284, 11431146.

23 P. Dalhaimer, F. S. Bates and D. E. Discher, Macromolecules, 2003, 36, 6873-6877.

24 P. Dalhaimer, A. J. Engler, R. Parthasarathy and D. E. Discher, Biomacromolecules, 2004, 5, 1714-1719.

25 F. Ahmed, A. Hategan, D. E. Discher and B. M. Discher, Langmuir, 2003, 19, 6505-6511.

26 Y. Geng and D. E. Discher, J. Am. Chem.Soc., 2005, 127, 12780-12781.

27 X. Wang, G. Guerin, H. Wang, Y. Wang, I. Manners and M. A. Winnik, Science, 2007, 317, 644-647.

28 H. Wang, W. Lin, K. P. Fritz, G. D. Scholes, M. A. Winnik and I. Manners, J. Am. Chem. Soc., 2007, 129, 12924-12925.

29 J. B. Gilroy, T. Gädt, G. R. Whittell, L. Chabanne, J. M. Mitchels, R. M. Richardson, M. A. Winnik and I. Manners, Nat. Chem., 2010, 2, 566-570.
30 T. Gadt, N. S. Ieong, G. Cambridge, M. A. Winnik and I. Manners, Nat. Mater., 2009, 8, 144-150.

31 N. Petzetakis, A. P. Dove and R. K. O'Reilly, Chem. Sci., 2011, 2, 955-960.

32 N. Petzetakis, D. Walker, A. P. Dove and R. K. O'Reilly, Soft Matter, 2012, 8, 7408-7414.

33 J. Chiefari, Y. K. Chong, F. Ercole, J. Krstina, J. Jeffery, T. P. T. Le, R. T. A. Mayadunne, G. F. Meijs, C. L. Moad, G. Moad, E. Rizzardo and S. H. Thang, Macromolecules, 1998, 31, 5559-5562.

34 G. Moad, E. Rizzardo and S. H. Thang, Polymer, 2008, 49, 1079-1131.

35 S. P. Rannard, N. C. Billingham, S. P. Armes and J. Mykytiuk, Eur. Polym. J., 1993, 29, 407-414.

36 N. Tirelli, M. P. Lutolf, A. Napoli and J. A. Hubbell, Rev. Mol. Biotechnol., 2002, 90, 3-15.

37 A. E. Smith, X. Xu and C. L. McCormick, Prog. Polym. Sci., 2010, 35, 45-93.

38 A. Blanazs, J. Madsen, G. Battaglia, A. J. Ryan and S. P. Armes, J. Am. Chem. Soc., 2011, 133, 16581-16587.

39 A. Blanazs, A. J. Ryan and S. P. Armes, Macromolecules, 2012, 45, 5099-5107.

40 D. Zehm, L. P. D. Ratcliffe and S. P. Armes, Macromolecules, 2012, 46, 128-139.

41 L. A. Fielding, M. J. Derry, V. Ladmiral, J. Rosselgong, A. M. Rodrigues, L. P. D. Ratcliffe, S. Sugihara and S. P. Armes, Chem. Sci., 2013, 4, 2081-2087.

42 X. Zhang, J. Rieger and B. Charleux, Polym. Chem., 2012, 3, 1502-1509.

43 J.-T. Sun, C.-Y. Hong and C.-Y. Pan, Soft Matter, 2012, 8, 7753-7767.

44 W.-M. Wan and C.-Y. Pan, Polym. Chem., 2010, 1, 14751484.

45 Y. Su, X. Xiao, S. Li, M. Dan, X. Wang and W. Zhang, Polym. Chem., 2014, 5, 578-587.

46 E. R. Jones, M. Semsarilar, A. Blanazs and S. P. Armes, Macromolecules, 2012, 45, 5091-5098.

47 L. Houillot, C. Bui, C. 1. Farcet, C. Moire, J.-A. Raust, H. Pasch, M. Save and B. Charleux, ACS Appl. Mater. Interfaces, 2010, 2, 434-442.

48 R. Verber, A. Blanazs and S. P. Armes, Soft Matter, 2012, 8, 9915-9922.

49 A. Blanazs, R. Verber, O. O. Mykhaylyk, A. J. Ryan, J. Z. Heath, C. W. I. Douglas and S. P. Armes, J. Am. Chem. Soc., 2012, 134, 9741-9748.

50 M. Semsarilar, V. Ladmiral, A. Blanazs and S. P. Armes, Langmuir, 2011, 28, 914-922.

51 C. Ratti, J. Food Eng., 2001, 49, 311-319.

52 J. C. Kasper, G. Winter and W. Friess, Eur. J. Pharm. Biopharm., 2013, 85, 162-169.

53 B. Cabane, S. Blanchon and C. Neves, Langmuir, 2006, 22, 1982-1990.

54 I. Cho and K. C. Chung, Macromolecules, 1988, 21, 565571.

55 L. Qi, A. Sehgal, J.-C. Castaing, J.-P. Chapel, J. R. M. Fresnais, J.-F. O. Berret and F. Cousin, ACS Nano, 2008, 2, 879-888. 
56 V. M. Gun'ko, I. N. Savina and S. V. Mikhalovsky, Adv. Colloid Interface Sci., 2013, 187-188, 1-46.

57 N. Yan, G. He, H. Zhang, L. Ding and Y. Fang, Langmuir, 2009, 26, 5909-5917.

58 J. Madsen, S. P. Armes, K. Bertal, S. MacNeil and A. L. Lewis, Biomacromolecules, 2009, 10, 1875-1887.
59 R. Zhang, H. K. Mjoseng, M. A. Hoeve, N. G. Bauer, S. Pells, R. Besseling, S. Velugotla, G. Tourniaire, R. E. B. Kishen, Y. Tsenkina, C. Armit, C. R. E. Duffy, M. Helfen, F. Edenhofer, P. A. de Sousa and M. Bradley, Nat. Commun., 2013, 4, 1335.

60 H. K. Kleinman and G. R. Martin, Semin. Cancer Biol., 2005, 15, 378-386. 